\title{
The GIS Principles and Applied Teaching Combined with That of the Urban Design Courses
}

\author{
Xixuan Fan*, Yan Xiao \\ School of Architecture and Fine Art, Dalian University of Technology, China \\ Email: fxx@dlut.edu.cn
}

\begin{abstract}
With the rapid development of information technology, all industries have entered the era of big data. As an important tool for data processing and analysis, GIS has gradually become an important tool in the construction and planning industry. At present, in undergraduate education in colleges and universities, GIS teaching has not yet formed a relatively complete system. There is a serious gap between GIS learning and applications, which is not conducive to student learning. Therefore, try to combine GIS with architectural design courses so that students can apply what they have learned and solidly grasp the learning content.
\end{abstract}

Keywords: GIS, joint teaching, architecture design course

\section{Application of GIS in the field of architecture}

With the development of the times, the construction and urban-rural planning industry has evolved from relatively simple craftsmanship technology in the early years to complex sciences including history, art, politics, society, geography, mathematics, etc., and the demand for professional qualities of architects has also become more diverse. In recent years, with the rapid development of the Internet and information technology, "digital technology" has emerged at the historic moment. Gary King, a sociology professor at Harvard University, said: "This is a revolution. The huge data resources have started the quantitative process in various fields This process will begin in all fields, whether in academia, business or government. ${ }^{,[1]}$ The construction industry has also joined the tide of digital transformation without exception.

Under the new data environment, researches ranging from large regional patterns to small architectural spaces have begun to shift to quantitative design. Under these conditions, GIS technology has gradually become a powerful tool in the fields of architecture and urban-rural planning. At the planning level, GIS can store the historical data of urban planning and predict the future development of the city. For example, in the development of Shatin New Town in Hong Kong, GIS is used to establish a land forecast management system. At the architectural level, GIS can be used for evacuation and evacuation routes of large public buildings Design can be used for building environmental risk assessment, and it can also store and analyze spatial data of building energy consumption. In addition, based on the powerful data visualization function of GIS, combined with virtual reality technology, it can also play an important role in building display and real estate project management. ${ }^{[2]}$

It can be seen that the current application of GIS technology in the construction field has achieved certain results, but most of the people who master GIS technology are non-architectural professionals. GIS education for students majoring in architecture and urban and rural planning still has a certain lag and needs to be targeted The vigorous promotion of the company serves the development of the digital and information construction industry.

\section{GIS teaching status}

At present, in the architecture teaching system of universities in China, GIS-related courses are roughly divided into two categories. One is a software training course based on ArcGIS software. It aims to make students understand the application of GIS technology through practical operations. Many possibilities; the other is the theoretical teaching based on the principles of GIS technology, which teaches the origin, development, data types, technical support of GIS, etc., with the goal of building a knowledge system.

\subsection{Software teaching based on ArcGIS operation}

Software application-based practical training can systematically improve students' application ability in a short time, so that students have an understanding of the specific operations of ArcGIS. However, because the data format, operation interface, and data processing mode of ArcGIS software are quite different from those used by traditional architecture majors, students need a certain theoretical accumulation. They are familiar with data types, analysis principles, and certain 
application cases. Only under the premise of the software operation.

\subsection{Theoretical teaching based on GIS principles}

In the undergraduate teaching of architecture, GIS technology is not commonly used, and it is widely used mainly in the postgraduate study stage. In view of this, combined with the particularity of ArcGIS software, some undergraduate GIS courses in architecture major are mainly theoretical teaching. Lectures on the history, development, and applications of GIS, as well as simple data types and data processing principles, achieve the purpose of constructing a knowledge system and lay a theoretical foundation for GIS applications at the graduate level.

\subsection{Existing problems in GIS teaching}

Whether it is software teaching based on practical operation or theoretical teaching based on GIS principles, it is of great significance for students to understand and understand GIS technology. However, under the current undergraduate teaching system, short-term teaching without practical applications makes it difficult for students to firmly grasp what they have learned, and it often becomes rusty or even forgotten due to lack of practice after the end of the course. Because of this, a GIS teaching concept combining with architectural design courses was put forward.

\section{Teaching of "GIS Principles and Applications" combined with the fourth-year architectural design course for undergraduates}

Dalian University of Technology's fourth-year undergraduate spring semester architectural design course includes two independent designs. Weeks 10-17 are urban design courses. The course of "Principles and Applications of GIS" undertaken by the author is from 1-12 weeks. Therefore, in the course teaching, the application of GIS technology in urban design is emphasized.

\subsection{Course Overview of Urban Design of Yan'an Road Area, Zhongshan District, Dalian}

Dalian is a window to the northeast of China and the largest port city. It is also an important economic, trade, industrial, and tourist city along the eastern coast. Zhongshan Plaza is located at the core of Dalian's Old Town. It is a comprehensive service center area that gathers central business, cultural and entertainment, apartment living and tourism shopping functions.

There are five plots planned in this urban design course. Students can choose one of them, combined with the detailed planning of Dalian urban area, according to the urban development and surrounding conditions of the plot, set up specific construction projects and scales for each plot. Create a complete urban open space that can reflect the local architectural context and urban development. In addition to the overall plan of the plan, a bird's eye view of the area, and the elevation of the open space along the street, the design results also emphasize the analysis of functions, traffic, and landscape. This also provides great possibilities for the application of GIS.

\section{2 "GIS Principles and Applications" course teaching combined with theory and operation}

In order to meet the needs of urban design courses to a greater extent, a combination of theory and practical operation is adopted in GIS courses for teaching. In addition to the GIS technology theories and principles that must be taught in traditional GIS courses, the GIS operation technologies that are directly related to urban design are selected, and some of the theories of urban design principles are further taught.

"GIS Principles and Applications" consists of 24 lessons and consists of 12 lessons, divided into three parts (see Table 1). 
Table 1. Teaching plan of GIS principles and applications

\begin{tabular}{|c|c|c|c|}
\hline $\begin{array}{l}\text { Teaching methods and } \\
\text { methods }\end{array}$ & session & \multicolumn{2}{|l|}{ Teaching content } \\
\hline \multicolumn{4}{|c|}{ Part I Theoretical lectures on the principles of GIS technology } \\
\hline \multirow{4}{*}{ multimedia } & 1 & \multicolumn{2}{|c|}{$\begin{array}{l}\text { Introduction: The development and current status of GIS spatial analysis technology, and examples of GIS } \\
\text { spatial analysis in practical applications. }\end{array}$} \\
\hline & 2 & \multicolumn{2}{|c|}{$\begin{array}{c}\text { Getting Started with GIS Coordinate System: Understand what are coordinate systems, what coordinate } \\
\text { systems are there, how to convert them, etc. }\end{array}$} \\
\hline & 3 & \multicolumn{2}{|c|}{$\begin{array}{l}\text { Getting started with ArcGIS: ArcGIS data types, data management, user interfaces, basic toolbars, and more. } \\
\text { Part two ArcGIS software operation combined with urban design principles }\end{array}$} \\
\hline & & Lecture on Urban Design Principles & ArcGIS software operations \\
\hline \multirow{9}{*}{ Multimedia + hands-on } & 4 & Architect's City View from "The Complete Street" & Drawing basics \\
\hline & 5 & Christopher Alexander, City is not a tree & \\
\hline & 6 & $\begin{array}{l}\text { Wu Wenyan's Study of the Collective Form and the Three Forms of } \\
\text { the City }\end{array}$ & Topics on spatial overlay analysis \\
\hline & 7 & Aldo Rossi’s “similar cities” theory & 3D Analysis Technology Topics \\
\hline & 8 & "Ecological city" concept and "green city" design & Landscape Sight Analysis Topics \\
\hline & 9 & Jan Gale, Communication and Space & \\
\hline & 10 & Kevin Lynch's Imagery of the City and Humanism & Traffic Network Analysis Topic \\
\hline & 11 & Awara Yoshinobu, "Outer Space Design" & \\
\hline & & \multicolumn{2}{|l|}{ Part III Comprehensive Application of ArcGIS in Urban Design } \\
\hline Multimedia & 12 & \multicolumn{2}{|c|}{ Evaluation and location of facilities and services in complex terrain } \\
\hline
\end{tabular}

Sections 1-3 are mainly based on the principles of GIS, which are part of the popularization of basic knowledge and the construction of knowledge systems. Considering the needs of architecture majors, there is no need to teach overly complicated and in-depth GIS theories. The main types are data types and coordinates. Department of theory and other theoretical knowledge, and through multiple cases to make students understand the application of GIS in daily life, to stimulate students' enthusiasm for learning.

Sections 4-11 are mainly based on software operations, which are composed of four topics: "spatial overlay analysis", "three-dimensional analysis", "landscape analysis", and "transport network analysis". Each topic is related to urban design courses. Technical requirements are directly related. In order to promote the better application of GIS technology in urban design in the future, each lesson is divided into two parts. The first part teaches related urban design knowledge based on the knowledge in this lecture, such as analyzing sections in the landscape view and penetrating. "Eco-city", "Green City", "Landscape City" and other concepts; In the "Transport Network Analysis" section, introduces Jan Gael, Kevin Lynch, Awara Yoshiyoshi, etc. on cities in terms of scale, boundary, and shape. Theories and methods of spatial evaluation. ${ }^{[3]}$ The second part focuses on the teaching of software operation corresponding to each topic, so that students can actually use the software, divergent thinking, and explore the applicability of the software on the basis of understanding the theory. ${ }^{[4]}$

The last part is the 12th session. Based on the theory and operation of the previous course, a comprehensive application case of urban design is used to review the knowledge learned throughout the process to form a complete knowledge system, so that students can further their skills and theory. Consolidation.

\subsection{Post-course application of GIS technology}

In the second major part of the course, the four thematic technologies selected have application space in "Urban Design of Yan'an Road Area, Zhongshan District, Dalian," and the two courses are basically connected in time. Therefore, students in the GIS course Immediately after the end, you can apply your knowledge to the actual design, which not only consolidates the knowledge learned in the course, but also provides a more logical quantitative method for the completion of the course design. Some students' application results are shown in Figure 1. 


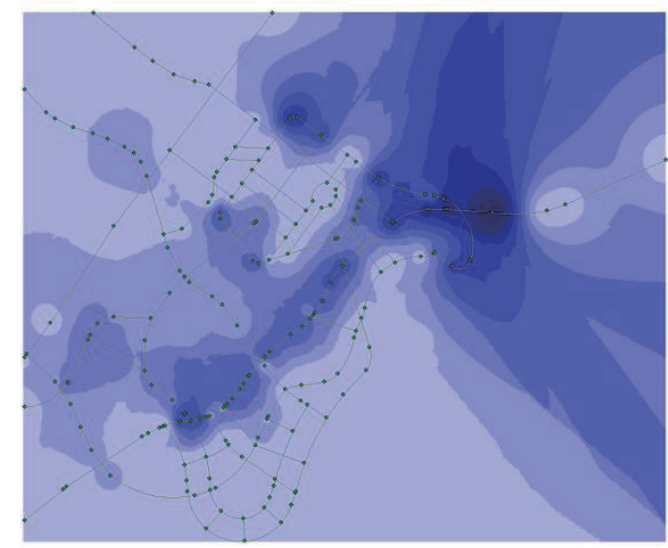

Figure 1. Availability analysis of urban design based on ArcGIS Image source: provided by student Li Rui

\section{Teaching summary and reflection}

Through the improvement of teaching methods and teaching goals, students' theory, practical operation and application scope of GIS technology have been further consolidated and improved. The course of "GIS Principles and Applications" ends in the form of a dissertation. The time is arranged after the assignment of urban design assignments. Students can further reflect on the knowledge and skills learned in the GIS course according to their application in the design course and consolidate what they have learned content. In view of the remarkable results of the existing results, the relationship between the two courses can be appropriately deepened in the future, so that students can learn and use the knowledge learned in the lectures and master them firmly. Summarizing the experience and problems of this course in teaching are as follows:

\subsection{Theoretical teaching corresponding to practical operations can strengthen students' memory}

It is found in teaching that compared with purely theoretical teaching or practical teaching, the combination of the two teaching methods can greatly improve students' memory. The boring theory is often forgotten after the class, or the memory is not solid, but the theory teaching combined with the actual urban design analysis can make students understand more thoroughly, the memory is more solid, and you can do the opposite The learning effect is very effective.

\subsection{It is more important to grasp the key practical operations}

In actual operation, because of the first contact, the operation interface of the software is very strange and the operation process is a bit complicated, and it is difficult for many students to remember the entire operation process systematically. This problem is particularly prominent at the beginning of teaching, so during the teaching process, pay attention to the key points of the extraction operation, deepen the student's memory through the connection of the key points, and ensure a smooth review after class.

\subsection{Continuing exercises after the course still need to be strengthened}

Although some operations have been carried out in the course, and at the same time, after the course, the technology learned can be directly applied to the urban design course, but this connection is still not enough. Students should be encouraged to apply this technology to all future course designs, be proficient in applying it, and constantly explore new analytical methods in order to apply what they have learned.

The above is only a preliminary exploration of GIS technology in undergraduate teaching. More thorough research and practice are needed. Inter-school and school-enterprise interactions should be strengthened to gradually improve the teaching of GIS technology in architecture. System to lay the foundation for students to apply in the future work and secondary school.

\section{References}

[1] Niu Qiang. GIS Technology Application Guide for Urban Planning. Construction Industry Press. Beijing: China; 2012.

[2] Song Yan, Peng Ke. GIS Application Guide for Urban Spatial Analysis. Construction Industry Press. Beijing: China; 
2015.

[3] Song Xiaodong, Niu Xinyi. Geographic Information System Practice Course. Science Press. Beijing. 2013.

[4] Xiang Zihao, Yuan Hongyuan. Analysis on the application of GIS in the field of architecture. Chinese Folk Houses. 2012; (12): 224. 